\title{
Pleomorphic adenoma of the lacrimal gland
}

\author{
Geoffrey E Rose, John E Wright
}

\begin{abstract}
To reduce the risk of recurrence and malignant transformation, pleomorphic adenomas of the lacrimal gland should be removed intact, without prior biopsy. Seventy one of the 78 patients in this series were referred without previous surgery, and, on clinical or radiological evidence, $63(89 \%)$ tumours were correctly diagnosed and totally excised, with preservation of a margin of the surrounding normal tissue. Sixty three patients had tumour within the body of the gland and $55(84 \%)$ had radiological signs or satisfied clinical criteria for pleomorphic adenoma that we suggested previously; that is, over 1 year of symptoms and absence of pain. Eight $(16 \%)$ orbital lobe tumours were misdiagnosed preoperatively and biopsied; in all these patients symptoms had been present for less than 1 year, and four patients had pain. Eight patients with tumours arising in the palpebral lobe had a short history of an upper lid mass, and their tumours were excised without biopsy. With the surgical techniques described in this paper, there has been no recurrence of tumour in patients with follow-up as long as $\mathbf{2 1}$ years. A modification of surgical technique, with preservation of the palpebral lobe of the gland, has reduced the incidence of postoperative dry eye and distortion of the upper eyelid.
\end{abstract}

Pleomorphic adenomas of the lacrimal gland have a high rate of recurrence if tumour cells are dispersed into the adjacent tissues during excision or biopsy, and recurrence are often malignant. ${ }^{1-3}$ Ideally these tumours should be diagnosed on radiological and clinical evidence and biopsy avoided.

An algorithm for the management of masses arising in the lacrimal gland fossa has been previously proposed by one of us. ${ }^{45}$ Highresolution computed tomography (CT) can help increase the proportion correctly diagnosed before surgery. ${ }^{6}$

The long-term results for 30 previously reported patients, ${ }^{5}$ together with those for a further 48 patients, are described in this paper, and the efficiency of our earlier diagnostic algorithm ${ }^{+}$is examined in relation to increased clinical and radiological experience. The results of a modified surgical technique are also described.

Orbital Clinic, Moorfields Eye Hospital, London EC1V 2PD G E Rose J E Wright Correspondence to: Mr J E Wright, Moorfields Eye Hospital, City Road, Eye Hospital, City Road, Accepted for publication 21 November 199
Between 1968 and 1990, 78 patients (40 male, 38 female) attended Moorfields Eye Hospital with pleomorphic adenoma of the lacrimal gland, representing about $2 \%$ of patients attending the Orbital Clinic.

A careful history was taken from all the patients, all underwent ophthalmological examination, and many were reviewed by a neurologist and a physician. Further investigation included orbital B-mode ultrasonography (to 1977), plain radiography or polytomography of the skull or orbits (65 patients), orbital venography (to 1974), or CT (from 1975; available for review for 54 patients).

Most patients have been treated according to our defined clinical algorithm. ${ }^{+}$In practice the patients may be classed into five principal groups:

(I) Patients undergoing resection of palpebral lobe tumours, with intact capsule, generally through a trans-septal approach.

(II) Patients having lateral orbitotomy and resection of tumours arising in the orbital lobe of the lacrimal gland.

(III) Patients who underwent trans-septal biopsy of tumours within the orbital portion of the lacrimal gland.

(IV) Patients undergoing lateral orbitotomy for orbital lobe tumours, together with the removal of the surgical track from previous biopsy (includes group (III) patients).

(V) Patients observed clinically (after excision of tumour at a referring hospital) or treated, after referral, for the recurrence of an incompletely excised tumour.

For tumours in the orbital lobe (groups II and IV) adequate access is possible only through a lateral orbitotomy.

TUMOUR RESECTION FROM THE ORBITAL LOBE OF THE LACRIMAL GLAND

Tumour resection is performed under general anaesthesia, by a modified lateral orbitotomy. ${ }^{7}$ The periorbita is elevated from the lateral wall and roof of the orbit; at all times the periorbita is retracted with a malleable brain retractor, the greatest care being taken to avoid a breach of the periorbita. The periosteum is incised inferiorly to the lower pole of the orbital part of the gland and the incision extended anteriorly and posteriorly, to beyond the palpable limits of the neoplasm. The incision is continued superiorly at either end of this incision, and the superior periorbita is incised medially to the upper pole of the gland, thereby mobilising the gland on an intact 'island' of free periorbita. The posterior pole of the gland is mobilised by transection of the neurovascular bundle entering the gland, and the mass is rolled forwards to ease the dissection. At all times the mass is manipulated with malleable retractors, and forceps are never used to handle the lesion. Microsurgical dissection is used to separate the mass from the levator muscle and its lateral horn and to identify the junction between the body of the gland and the palpebral lobe. The gland is transected at this junction, as it curves round the lateral horn of the levator muscle. A margin of normal tissue is always left in contact with the tumour mass, and 
it is sometimes necessary to sacrifice parts of neighbouring structures.

In the earlier cases of the series dissection was continued anteriorly, inferior to the lateral horn of the levator aponeurosis, and the palpebral lobe and ductules of the lacrimal gland were resected; the resulting conjunctival defect was left open to allow free drainage of fluid from the resection site. In more recent cases, if the mass is located solely within the orbital portion of the gland, the isthmus between the orbital and the palpebral lobes is transected at a site clear of the tumour and the palpebral lobe is preserved.

Where a specimen of tumour has been taken for biopsy, the biopsy track and skin scar are excised, in continuity with a total dacryoadenectomy, the aim being to reduce the risk of recurrent disease at the previous biopsy site.

\section{TUMOUR RESECTION FROM THE PALPEBRAL LOBE} OF THE LACRIMAL GLAND

Palpebral lobe tumours are resected through an anterior (trans-septal) orbitotomy, though lateral orbitotomy was used in two cases where the posterior extent of the tumour was unclear. The lacrimal ductules and surrounding conjunctiva are resected, along with a 'cuff' of normal tissues, and the isthmus between the palpebral lobe and the body of the gland is divided. In some cases division of the lateral horn of levator aponeurosis is necessary, being repaired after removal of the tumour.

Table 1 Epidemiology and presenting symptoms of patients with pleomorphic adenoma of the lacrimal gland

\begin{tabular}{llll}
\hline & $\begin{array}{l}\text { Group I: } \\
\text { palpebral lobe } \\
\text { tumours } \\
(8 \text { cases })\end{array}$ & $\begin{array}{l}\text { Groups II and IV: } \\
\text { orbital lobe tumours (65 cases) }\end{array}$ \\
\cline { 4 - 4 } Characteristic or symptom & $\begin{array}{l}\text { Not biopsied } \\
(55)\end{array}$ & $\begin{array}{l}\text { Biopsied } \\
(10)\end{array}$ \\
\hline Age at first symptom & & & \\
(years); mean, range & $46(22-79)$ & $47(17-79)$ & $40(18-65)$ \\
Sex $(M: F)$ & $5: 3$ & $28: 27$ & $4: 6$ \\
Laterality (R:L) & $5: 3$ & $35: 20$ & $4: 6$ \\
Symptom duration at lst & $0 \cdot 9(0 \cdot 1-1 \cdot 9)$ & $2 \cdot 2(0 \cdot 1-19)$ & $2 \cdot 6(0 \cdot 1-20)$ \\
ophthalmic consultation (yr); mean & & & $0 \cdot 25(0 \cdot 1-0 \cdot 6)^{\star}$ \\
range & - & $42(76 \%)$ & $5(50 \%)$ \\
Proptosis & - & $22(40 \%)$ & $4(40 \%)$ \\
Diplopia & $8(100 \%)$ & $14(25 \%)$ & $4(40 \%)$ \\
Swelling/lump & $-15(27 \%)$ & $3(30 \%)$ \\
Visual change & $2(25 \%)$ & $17(31 \%)$ & $1(10 \%)$ \\
Lacrimation & $1(12 \%)$ & $6(11 \%)$ & $4(40 \%)$ \\
Discomfort & - & $8(15 \%)$ & $1(10 \%)$ \\
Ptosis & &
\end{tabular}

^Excludes two cases biopsied before referral from other hospitals.

Table 2 Clinical signs and preferred preoperative diagnoses for patients with lacrimal pleomorphic adenoma

\begin{tabular}{|c|c|c|c|}
\hline \multirow[b]{2}{*}{ Clinical sign } & \multirow{2}{*}{$\begin{array}{l}\text { Group I: } \\
\text { palpebral lobe } \\
\text { tumours } \\
(8 \text { cases })\end{array}$} & \multicolumn{2}{|c|}{$\begin{array}{l}\text { Groups II and IV: } \\
\text { orbital lobe tumours ( } 65 \text { cases) }\end{array}$} \\
\hline & & $\begin{array}{l}\text { Not biopsied } \\
\text { (55) }\end{array}$ & $\begin{array}{l}\text { Biopsied } \\
(10)\end{array}$ \\
\hline \multirow{2}{*}{$\begin{array}{l}\text { Palpable mass } \\
\text { Relative proptosis }(\mathrm{mm}) \text {; } \\
\text { mean, range }\end{array}$} & $8(100 \%)$ & $53(96 \%)$ & $10(100 \%)$ \\
\hline & $\begin{array}{l}0 \cdot 7(0-2) \\
(6 \text { cases })\end{array}$ & $\begin{array}{l}5 \cdot 7(0-13) \\
(54 \text { cases })\end{array}$ & $4 \cdot 1(0-9)$ \\
\hline Displacement of the globe off axis & $1(12 \%)$ & $52(95 \%)$ & $9(90 \%)$ \\
\hline Restricted ocular movement & $1(12 \%)$ & $44(80 \%)$ & $8(80 \%)$ \\
\hline Ptosis & $2(25 \%)$ & $10(18 \%)$ & $2(20 \%)$ \\
\hline $\begin{array}{l}\text { Reduced acuity } \\
\text { Swollen optic disc or optic atrophy }\end{array}$ & ${ }_{-}^{1(12 \%)}$ & $17(31 \%)$ & $\begin{array}{l}3(30 \%) \\
2(20 \%)\end{array}$ \\
\hline Choroidal folds & - & $21 / 53(40 \%)$ & $3(30 \%)$ \\
\hline $\begin{array}{l}\text { Preoperative diagnoses } \\
\text { Pleomorphic adenoma }\end{array}$ & $7(88 \%)$ & $51(93 \%)$ & - \\
\hline Carcinoma/lymphoma & - & - & $8(100 \%)$ \\
\hline Dacryoadenitis & & - & $4(50 \%)$ \\
\hline Dermoid or other & $3(37 \%)$ & $8(15 \%)$ & - \\
\hline
\end{tabular}

^ Reduction of two or more Snellen grades below fellow eye.

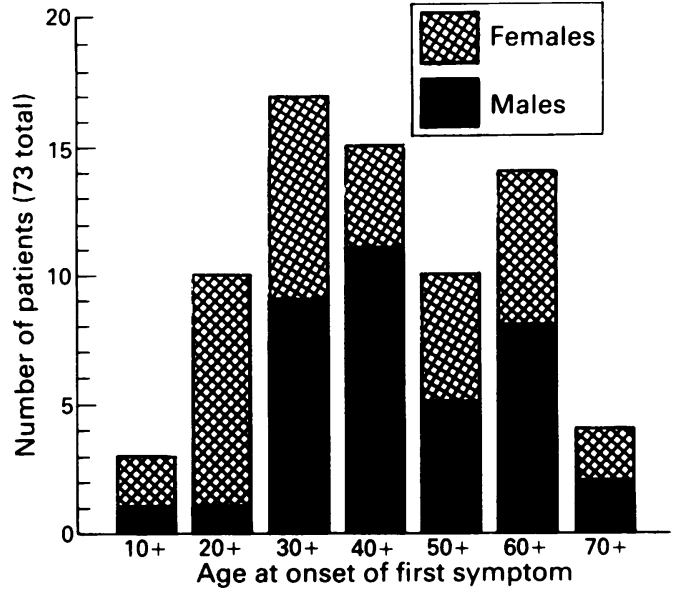

Figure 1 Age (at onset of first symptom) and sex distribution of patients with pleomorphic adenoma of the lacrimal gland.

\section{Results}

The age at presentation conforms to a Gaussian distribution (Fig 1) and the incidence is similar in the two sexes (Table 1, Fig 1). However, the duration of the first symptom (Fig 2) and the nature of the presenting symptoms (Table 1) or signs (Table 2) vary for lesions in the different parts of the gland.

\section{CLINICAL PRESENTATION AND MANAGEMENT}

Seventy one of the 78 patients $(91 \%)$ had newly presenting disease, of whom eight $(11 \%)$ had masses located within the palpebral lobe (Group I). Excision of these tumours, with a clear margin of tissue, was without surgical complication.

Sixty three $(89 \%)$ of the new patients had tumours in the body of the gland, of which 55 (87\%) were considered preoperatively to be pleomorphic adenomas or dermoids (Table 2), having had symptoms longer than a year (69\%), an absence of pain (89\%), or radiographic changes compatible with a long-standing mass lesion. These 55 tumours were resected intact through a lateral orbitotomy (group II), though in five cases the 'pseudocapsule' of the tumour was thin or adherent to neighbouring bone. Resection of bone was required in five cases and intraoperative spillage of tumour cells possibly occurred in four

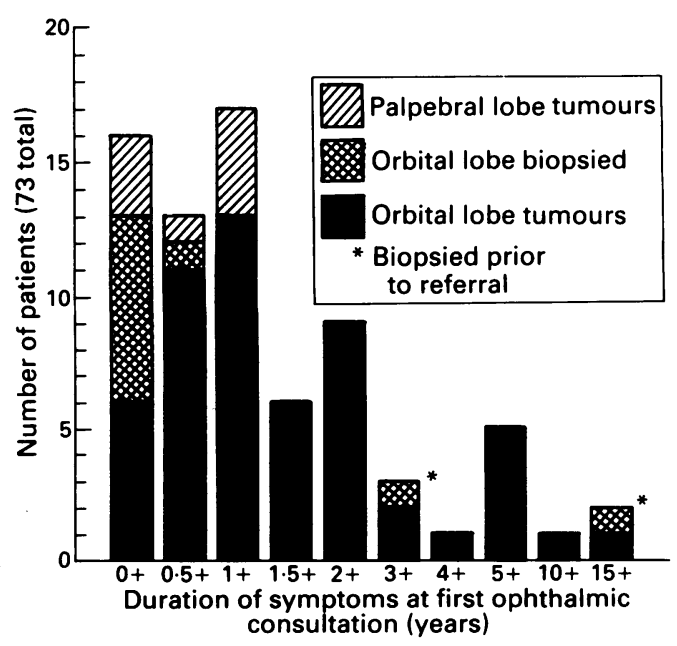

Figure 2 Duration of initial symptom (at first ophthalmic consultation) for patients with pleomorphic adenoma of the lacrimal gland. 
Table 3 Surgical resection of pleomorphic adenoma: intraoperative findings and postoperative follow-up interval, complications, and therapy

\begin{tabular}{|c|c|c|c|c|}
\hline \multirow[b]{3}{*}{$\begin{array}{l}\text { Surgical detail } \\
\text { and follow-up }\end{array}$} & \multirow[b]{3}{*}{$\begin{array}{l}\text { Palpebral lobe } \\
\text { (Group I) tumours } \\
(8)\end{array}$} & \multicolumn{3}{|c|}{ Orbital lobe tumours (65) } \\
\hline & & \multicolumn{2}{|c|}{ Not biopsied (group II) } & \multirow[b]{2}{*}{$\begin{array}{l}\text { Biopsied } \\
\text { (group IV) tumours } \\
\text { (10) }\end{array}$} \\
\hline & & $\begin{array}{l}\text { Partial adenectomy } \\
\text { (26) }\end{array}$ & $\begin{array}{l}\text { Total adenectomy } \\
\text { (29) }\end{array}$ & \\
\hline $\begin{array}{l}\text { Pressure erosion of } \\
\text { orbital bone } \\
\text { Periosteal breach or }\end{array}$ & - & $2(8 \%)$ & $1(3 \%)$ & $1(10 \%)$ \\
\hline 'pseudocapsule' & - & $3(12 \%)$ & $2(7 \%)$ & $2(20 \%)$ \\
\hline \multicolumn{5}{|c|}{ Follow-up interval from time of treatment (years) } \\
\hline Mean & 1.9 & 1.5 & $7 \cdot 8$ & 6.0 \\
\hline Number $\geq 5 \mathrm{yr}$ & - & $2(8 \%)$ & $18(62 \%)$ & $4(40 \%)$ \\
\hline Number $\geq 10 \mathrm{yr}$ & - & - & $12(40 \%)$ & $2(20 \%)$ \\
\hline Number $\geq 15$ yr & - & - & $4(13 \%)$ & - \\
\hline Number $\geq 20 \mathrm{yr}$ & - & - & $2(7 \%)$ & $1(10 \%)$ \\
\hline
\end{tabular}

(Table 3). An intraoperative breach of dura mater occurred in one patient, in whom the orbital roof was eroded by the tumour.

In $8 / 63(13 \%)$ patients (group III) symptoms were present for less than 1 year and the preoperative diagnosis was malignancy or chronic dacryoadenitis (Table 2). Symptoms had been present for 2 weeks to 7 months at first referral to an ophthalmologist, and half of these patients had pain (in contrast to only six (11\%) of group II patients). All patients in group III had tumour biopsy (between 6 weeks and 11 months after their first symptom) and, when histological diagnosis was available, underwent lateral orbitotomy, total dacryoadenectomy, and removal of the biopsy track (Group IV); in two patients the tumour was adherent to the bone of the lateral orbital wall.

Seven patients (9\%) had biopsy proved disease prior to referral: two, with symptoms for 4 and 20 years prior to biopsy, underwent lateral orbitotomy with total dacryoadenectomy and removal of the biopsy track (group IV). Tumour recurrence in two patients (at 2 and 4 years after incomplete excision was treated by radical excision and exenteration, respectively. Another patient had a tumour recurrence at 44 years after initial surgery, the resected specimen proving to be malignant. Two patients, referred after incomplete excision of tumour, are being reviewed regularly without further treatment (group V). skull showing expansion of the left lacrimal gland fossa by an orbital lobe

pleomorphic adenoma.

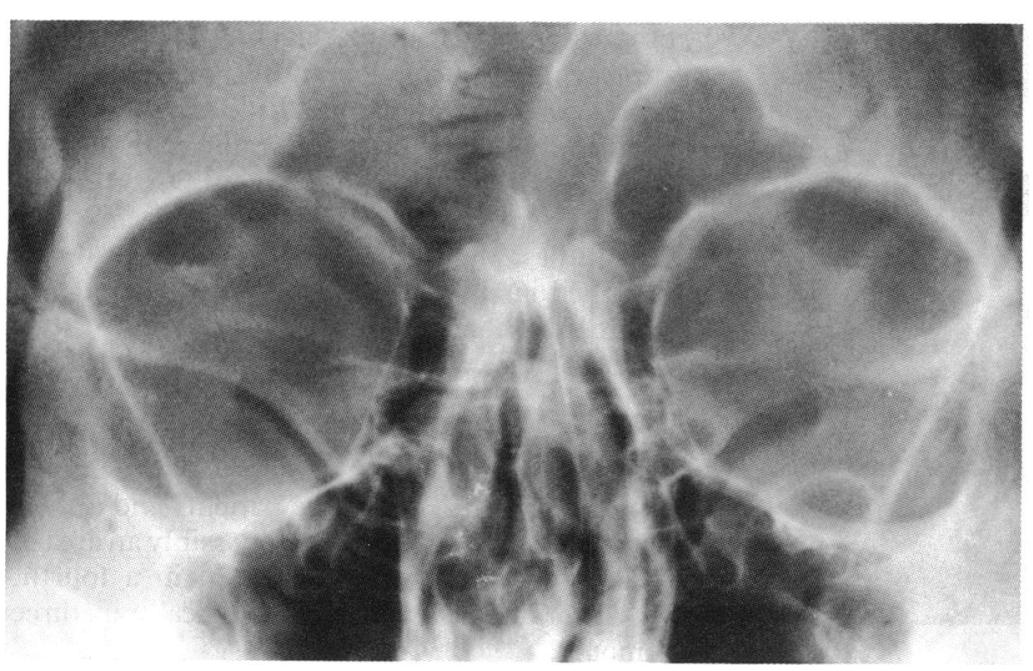

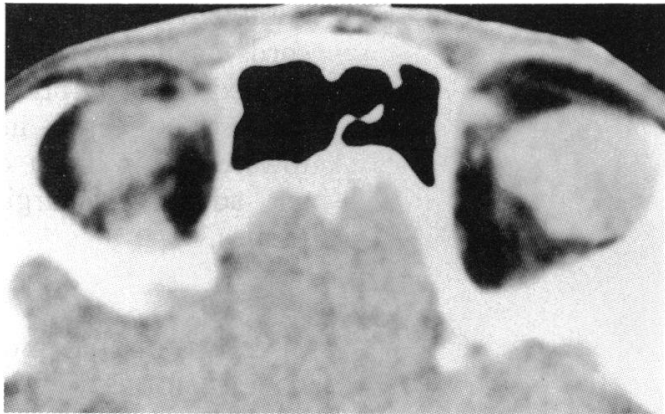

Figure 4 Well defined mass on axial CT scan, commonly seen with pleomorphic adenoma of the orbital lobe of the lacrimal gland.

\section{RADIOLOGY}

Orbital lobe tumours caused visible erosion of the bone of the lacrimal fossa in 52/53 patients (98\%) whose studies were available for review; it was detectable on plain films (13 cases; Fig 3) or CT ( 45 cases). Although eight CT studies showed a breach of the orbital roof, this did not display the irregular destruction seen with some malignant neoplasms.

A well defined soft-tissue mass was shown on CT scan in orbital lobe adenomas (Fig 4), but in only few palpebral lobe tumours. Calcification within the body of the gland was visible on four CT studies at soft-tissue windows and was reported pathologically in three (Fig 5A).

\section{EFFECT OF MODIFIED SURGICAL TECHNIQUE ON} CLINICAL OUTCOME

With preservation of the palpebral lobe, there was a significant $(p<0.001)$ reduction in the incidence of keratoconjunctivitis sicca and the need for topical ocular lubricants (Table 4).

The frequency of other complications is similar in the various groups (Table 4). In the minority of patients experiencing diplopia after lateral orbitotomy, this tended to occur only on extremes of horizontal gaze. Similarly, the degree of ptosis was generally mild, required surgical correction in only five cases.

\section{LENGTH OF FOLLOW-UP INTERVALS}

In $43 / 73(59 \%)$ of patients who underwent primary resection of a tumour the most recent review was in (or after) 1989. Thirty patients who defaulted to follow-up were all free of disease at last clinical examination; many regard the benign tumour as cured, without complication, and hence the relatively high number of defaulters.

The duration of follow-up varies from $0 \cdot 2-4 \cdot 7$ years for group I, $0 \cdot 1-21 \cdot 5$ years for group II, and $0 \cdot 5-19 \cdot 7$ years for groups III and IV (Table 3).

\section{Discussion}

Up to half of intrinsic lacrimal gland masses ${ }^{48-12}$ are neoplasms of epithelial origin, of which many are pleomorphic adenomas (benign mixed tumours) derived from the ducts, stroma, and myoepithelial elements of the lacrimal gland. ${ }^{13}$ 
Although benign tumours, they show cellular cords extending outwards into a 'pseudocapsule,' formed by compression of the surrounding tissues. ${ }^{14}$ Resection must therefore be directed towards their intact excision, with removal of an adequate margin of the surrounding tissues. ${ }^{124514}$ 15

\section{OUTCOME AFTER INTACT EXCISION OF ORBITAL} LOBE TUMOURS

With an algorithm proposed previously ${ }^{4} 55 / 63$ $(87 \%)$ patients were correctly diagnosed preoperatively as requiring a lateral orbitotomy for excision of a benign mass in the body of the lacrimal gland; $69 \%$ had symptoms for a year or more prior to ophthalmic consultation, $89 \%$ were without pain, and almost all (98\%) had radiographic evidence of a well defined mass eroding (rather than invading) the bone of the lacrimal fossa.

There have been no tumour recurrences in this group (Table 3: group II; 55 patients), though the tendency to late recurrence of such tumours precludes a true assessment of 'cure rate' until several decades after treatment.

OUTCOME AFTER BIOPSY AND LATER EXCISION OF ORBITAL LOBE TUMOURS

Orbital lobe tumours were biopsied in eight patients $(13 \%)$ because of a short history ( 2 weeks to 7 months) and the presence of pain in four (group III). A short history and pain were considered indicative of malignant change, though, in some, CT displayed features of a benign tumour. ${ }^{6}$ Two other patients, both with long histories, were biopsied at the referring hospitals.

All 10 patients underwent lateral orbitotomy, total dacryoadenectomy, and removal of the biopsy track. A limited follow-up for group IV

Figure 5 Calcification in pleomorphic adenomas $(A)$ is rare, in comparison with that within lacrimal gland carcinomas $(B)$.

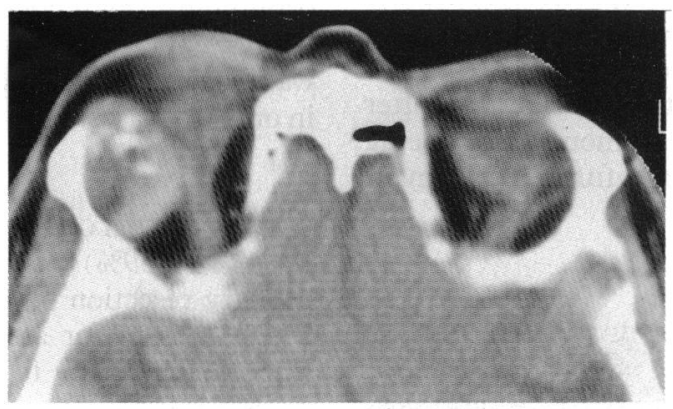

Fig $\dot{5} A$

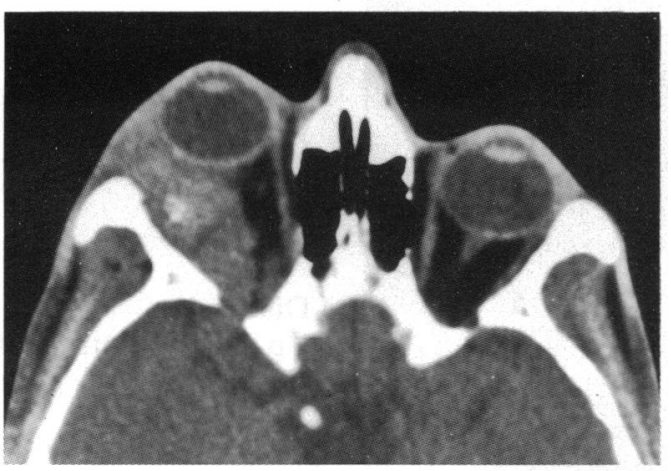

Fig 5B makes assessment of a 'cure rate' impossible, but it is encouraging that there have been no tumour recurrences after as long as 20 years (Table 3).

The potentially disastrous consequences of the incomplete removal of a pleomorphic adenoma have been emphasised by Font and Gamel, ' who reported an overall 15-year recurrence rate of $30 \%$. Initial management was critical for prognosis, with a 5-year recurrence rate of $3 \%$ if the tumour was totally removed, in contrast to $32 \%$ if the tumour was biopsied prior to removal. Recurrent pleomorphic adenoma can undergo malignant change, as in a third of patients first presenting to us with recurrent tumour (group V): Font and Gamel' estimate, actuarially, that about $10 \%$ of adenomas undergo malignant change by 20 years after first treatment and $20 \%$ by 30 years. Recurrence and malignant change of adenomas after incomplete excision are also reported in other series. ${ }^{3}$

Because biopsy of pleomorphic adenomas has such an adverse influence upon the long term outcome, it clearly is preferable that these tumours are diagnosed before surgery and that biopsy is avoided.

CLINICAL AND RADIOLOGICAL DIAGNOSIS OF PLEOMORPHIC ADENOMAS

Diagnosis of palpebral lobe tumours is usually straightforward. ${ }^{16}{ }^{17}$ Patients give a short history (often less than a year: Table 1, Fig 2) of a painless, mobile, hard mass in the lateral aspect of the upper eyelid. High-resolution CT may demonstrate a mass at, or anterior to, the orbital rim and no radiological changes within the oibital lobe of the gland. Excisional biopsy of palpebral lobe tumours, with an adequate margin of normal tissue, is both curative and diagnostic.

Diagnosis of tumours within the body of the lacrimal gland is more difficult. They often present as a slowly progressive mass (Tables 1 and 2) with symptoms such as facial asymmetry (72\%) diplopia (40\%), or swelling (28\%), commonly noted for many years before referral. Lacrimation, often episodic, was a presenting symptom in some patients (Table 1), this symptom being rare in patients with lacrimal gland carcinoma. ${ }^{18}$

The chronic nature of orbital lobe tumours is reflected in often extreme degrees of slowly progressive ocular displacement - here varying, at presentation, from $0 \mathrm{~mm}$ to $13 \mathrm{~mm}$ of relative proptosis and inferomedial displacement (Table 2). It is also evident radiologically, with erosion of the lacrimal fossa by a smoothly contoured mass present in $70 \%$ plain films (Fig 3) and $81 \%$ CT studies; the orbital roof or lateral wall was breached in eight cases. There was no evidence of irregular bone invasion or destruction.

Radiological evidence of calcification within benign lesions of the lacrimal fossa is rare ${ }^{19}$ and is more common with carcinomas ${ }^{18}$ (Fig 5B). In this series diffuse calcification was present on high-resolution CT in three patients and a large nodule of dense calcification - possibly an area of osseus differentiation - was seen in a fourth. Calcification was evident histologically in three tumours. 
Table 4 Frequency of late complication (more than 6 months after surgery) in patients undergoing total or partial dacryoadenectomy

\begin{tabular}{llll}
\hline Complication & $\begin{array}{l}\text { Palpebral lobe preserved } \\
(28)\end{array}$ & $\begin{array}{l}\text { Palpebral lobe excised } \\
(45)\end{array}$ & Significance $(p)$ \\
\hline Diplopia extremes of gaze & $7(25 \%)$ & $14(31 \%)$ & $>0.05$ \\
Ptosis present & $7(25 \%)$ & $13(29 \%)$ & $>0.05$ \\
Ptosis surgery required & $1(4 \%)$ & $4(9 \%)$ & $>0.05$ \\
Symblepharon & - & $5(11 \%)$ & $>0.05$ \\
Filamentary keratopathy & $7(25 \%)$ & $35(78 \%)$ & $<0.001$ \\
Topical lubricants required & $6(21 \%)$ & $28(62 \%)$ & $<0.001$ \\
Occlusion of puncta & - & $6(13 \%)$ & 0.05 \\
\hline
\end{tabular}

Table 5 Number of patients with pleomorphic adenomas (66) or carcinomas (46) arising in the orbital lobe of the lacrimal gland, classed according to the presence or absence of pain and the duration of initial symptom at the time of first ophthalmic consultation; percentages (in brackets) refer to portions across the rows

\begin{tabular}{|c|c|c|c|c|}
\hline \multirow[b]{2}{*}{$\begin{array}{l}\text { Duration of } \\
\text { symptoms }\end{array}$} & \multicolumn{2}{|c|}{ Painless (69) } & \multicolumn{2}{|c|}{ Painful (43) } \\
\hline & $\begin{array}{l}\text { Adenomas } \\
(56)\end{array}$ & $\begin{array}{l}\text { Carcinomas } \\
\text { (13) }\end{array}$ & $\begin{array}{l}\text { Adenomas } \\
\text { (10) }\end{array}$ & $\begin{array}{l}\text { Carcinomas } \\
\text { (33) }\end{array}$ \\
\hline $\begin{array}{l}<8 \text { months }(45) \\
8-12 \text { months }(19) \\
>12 \text { months }(48)\end{array}$ & $\begin{array}{r}11(24 \%) \\
9(46 \%) \\
36(75 \%)\end{array}$ & $\begin{array}{l}11(24 \%) \\
2(11 \%) \\
0\end{array}$ & $\begin{array}{l}4(9 \%) \\
2(11 \%) \\
4(8 \%)\end{array}$ & $\begin{array}{c}19(43 \%) \\
6(32 \%) \\
8(17 \%)\end{array}$ \\
\hline
\end{tabular}

Table 6 Management plan for masses within the orbital lobe of the lacrimal gland

\begin{tabular}{|c|c|c|}
\hline \multirow[b]{2}{*}{ Characteristic } & \multicolumn{2}{|l|}{ Score } \\
\hline & -1 & +1 \\
\hline $\begin{array}{l}\text { Clinical: } \\
\text { Duration of acute symptoms } \\
\text { Persistent pain } \\
\text { Sensory loss } \\
\text { Radiological } \\
\text { Well-defined round or oval } \\
\text { mass } \\
\text { Moulding of mass to globe or } \\
\text { along the lateral orbital wall } \\
\text { Tumour calcification } \\
\text { Invasion of bone } \\
\text { Duration of symptoms in } \\
\text { relation to the tumour size }\end{array}$ & $\begin{array}{l}\text { Absent } \\
\text { Present } \\
\text { Present } \\
\text { Present } \\
\text { Large tumour; } \\
\quad \text { short } \\
\text { symptoms }\end{array}$ & $\begin{array}{l}\text { Present } \\
\text { Absent } \\
\text { Absent } \\
\text { Absent } \\
\text { Small tumour; } \\
\quad \text { long } \\
\text { symptoms }\end{array}$ \\
\hline
\end{tabular}

^ Features on high-resolution CT studies

Total score: -8 to +2 , probably carcinoma (for incisional biopsy); -6 to +2 , probably malignant mixed tumour (for incisional or excisional biopsy); +3 to +8 , probably pleomorphic adenoma (for excision without prior biopsy).

\section{MODIFIED ALGORITHM FOR THE MANAGEMENT OF} LACRIMAL GLAND MASSES

The clinical algorithm, proposed previously for the preoperative differentiation of benign from malignant lacrimal gland tumours, ${ }^{4}$ may now be modified because of our greater clinical experience ${ }^{18}$ and improved radiological imaging.

On grouping the patients according to the presence or absence of pain and the duration of symptoms at first ophthalmic consultation, it is evident that the original clinical algorithm ${ }^{4}$ is still valid (Table 5); namely, that painful, shortduration lesions ${ }^{18}$ favour carcinomas and the converse characteristics favour adenomas. However, we now find that greater discrimination (between carcinomas and adenomas) occurs at 10 months, rather than 12 months, as originally suggested.

Although biopsy was recommended ${ }^{4}$ for lesions causing symptoms for less than 1 year, especially if painful (as likely to be carcinoma), we now avoid biopsy if CT shows a smoothly contoured mass expanding the orbit, suggesting a benign lesion. ${ }^{6}$ The presence of tumour calcification, significantly more common with carcinomas, ${ }^{18}$ favours biopsy.

A modified plan for the management of persistent masses in the lacrimal gland, taking into account the changes in clinical and radiological diagnosis, is given in Table 6. Low scores for the clinical and radiological features favour the diagnosis of carcinoma (for incisional biopsy), whereas higher scores favour pleomorphic adenoma (for intact excisional biopsy).

\section{COMPLICATIONS OF SURGERY AND MODIFIED}

SURGICAL TECHNIQUE

With the techniques used, intraoperative complications were few. Intraoperative breach of dura mater in one patient was treated by local application of Gelfoam strips and the administration of systemic antibiotics, with uneventful postoperative recovery. If it was considered that the 'pseudocapsule' of the tumour might have been breached during surgery, this was treated by strict surgical isolation, lavage of the operative field after removal of the mass and, where possible, wide excision of neighbouring tissues.

A modified surgical approach for tumours of the orbital lobe, within transection of the isthmus between the orbital and palpebral lobes (and preservation of the latter) provides a significant reduction in corneal surface changes and the need for long-term topical therapy (Table 4). The frequency of persistent diplopia on extreme gaze and ptosis (the latter requiring correction in some cases) was similar in patients after partial or total dacryoadenectomy (Tables 3 and 4); these complications generally result from the lateral orbitotomy and the occasional need for resection of structures neighbouring the tumour, rather than being a direct consequence of the extent of dacryoadenectomy.

At present the numbers of patients free of disease after more than 10 years ( 14 cases), 15 years (five cases), or 20 years ( 3 cases) is encouraging. However, only another 10 or 20 years of follow-up will determine whether partial dacryoadenectomy, with its lower complication rate, is a safe treatment for pleomorphic adenomas of the orbital lobe. Our thanks are due to the many consultant ophthalmic surgeons who referred cases to the Orbital Clinic, to Professor A Garner and his colleagues for the histopathology, to Drs G Lloyd and I Moseley for their radiological skills, and to the staff of the Department of Medical Illustration, Moorfields Eye Hospital, for
clinical photography. We are particularly grateful to Dr Ivan Moseley for his most helpful review of the manuscript.

1 Font RL, Gamel JW. Epithelial tumours of the lacrimal gland an analysis of 265 cases. In: Jakobiec FA, ed. Ocular and adnexal tumours. Birmingham: Aesculapius, 1978: 787-805.

2 Henderson JW, Farrow GM. Orbital tumeurs. 2nd ed. New York: Decker, 1980.

3 Ni C, Cheng SC, Dryja TP, Cheng TY. Lacrimal gland umors. A clinicopathological analysis of 160 cases. In Ophthalmol Clin 1982; 22: 99-120.

4 Wright JE, Stewart WB, Krohel GB. Clinical presentation and management of lacrimal gland tumours. Br $\mathcal{F}$ Ophthalmo 1979; 63: 600-6

5 Wright JE. Factors affecting the survival of patients with lacrimal gland tumours. Can f Ophthalmol 1982; 17: 3-9.

6 Jakobiec FA, Yeo JH, Trokel SL, Abbott GF, Anderson R, Citrin CM. Combined clinical and computed tomographic diagnosis of primary lacrimal fossa lesions. Am $\mathcal{F}$ Ophthalmol 1982; 94: 785-807.

7 Wright JE. Orbitotomy. In: Heilmann K, Paton D, eds. Atlas of ophthalmic surgery. Ist ed. Stuttgart and New York: Thieme, 1985: 3.12-3.22.

8 Rootman JA. Diseases of the orbit. A multidisciplinary approach. Philadelphia: Lippincott, 1988.

9 Reese AB. The treatment of expanding lesions of the orbit: with particular reference to those arising in the lacrimal gland. Seventh Arthur J. Bedell lecture. Am $\mathcal{F}$ Ophthalmol 1956; 41: 3-11. 
10 Kennedy RE. An evaluation of 820 orbital cases. Trans $A m$ Ophthalmol Soc 1984; 82: 134-57.

11 Shields JA, Bakewell B, Augsburger JJ, Flanagan JC Classification and incidence of space-occupying lesions of the orbit: a survey of 645 biopsies. Arch Ophthalmol 1984; the orbit: a

12 Shields CL, Shields JA, Eagle RC, Rathmell JP. Clinicopathologic review of 142 cases of lacrimal gland lesions. Ophthalmology 1989; 96: 431-5.

13 Grossniklaus HE, Abbuhl MF, McLean IW. Immunohistologic properties of benign and malignant mixed umor of the lacrimal gland. Am 7 Ophthalmol 1990; 110 $540-9$.

14 Zimmerman LE, Sanders TE, Ackerman LV. Epithelial tumors of the lacrimal gland: prognostic significance of histologic types. Int Ophthalmol Clin 1962; 2: 337-67.
15 Jakobiec FA. Tumors of the lacrimal gland and lacrimal sac. In: Anderson RL, et al, eds. Symposium of diseases and surgery of the lids, lacrimal apparatus and orbit. (Trans New Orleans of the lids, lacrimal apparatus and orbit. (Trans New
Acad Ophthalmol). St Louis: Mosby, 1982: 190-202.

16 Auran J, Jakobiec FA, Krebs W. Benign mixed tumor of the palpebral lobe of the lacrimal gland. Clinical diagnosis and palpebral lobe of the lacrimal gland. Clinical diagnosis and
appropriate surgical management. Ophthalmology 1988; 95: $90-9$

17 Parks SL, Glover AT. Benign mixed tumours arising in the palpebral lobe of the lacrimal gland. Ophthalmology 1990 97: $526-30$.

18 Wright JE, Rose GE, Garner A. Primary malignant tumours of the lacrimal gland. Br $\mathcal{F}$ Ophthalmol 1992; 76: 401-7.

19 Portis JM, Krohel GB, Stewart WB. Calcifications in lesions of the fossa of the lacrimal gland. Ophthalmic Plast Reconstr Surg 1985; 1: 137-44. 